\title{
Mechanisms of sudden cardiac death
}

\author{
Michael Rubart1,2 and Douglas P. Zipes'
}

${ }^{1}$ Krannert Institute of Cardiology and 2Wells Center for Pediatric Research, Indiana University School of Medicine, Indianapolis, Indiana, USA.

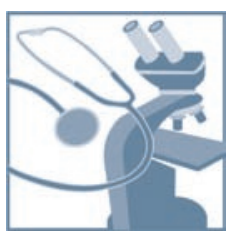

Despite recent advances in preventing sudden cardiac death (SCD) due to cardiac arrhythmia, its incidence in the population at large has remained unacceptably high. Better understanding of the interaction among various functional, structural, and genetic factors underlying the susceptibility to, and initiation of, fatal arrhythmias is a major goal and will provide new tools for the prediction, prevention, and therapy of SCD. Here, we review the role of aberrant intracellular $\mathrm{Ca}^{2+}$ handling, ionic imbalances associated with acute myocardial ischemia, neurohumoral changes, and genetic predisposition in the pathogenesis of SCD due to cardiac arrhythmia. Therapeutic measures to prevent SCD are also discussed.

Sudden cardiac death (SCD) from any cause claims 300,000400,000 lives a year in the United States. The most common sequence of events leading to SCD appears to be the degeneration of ventricular tachycardia (VT; abnormal acceleration of ventricular rate) into ventricular fibrillation (VF), during which disorganized contractions of the ventricles fail to eject blood effectively, often followed by asystole or pulseless electrical activity. Preexisting coronary artery disease and its consequences (acute myocardial ischemia, scarring from previous myocardial infarction, heart failure) are manifest in $80 \%$ of SCD victims. Dilated nonischemic and hypertrophic cardiomyopathies account for the second largest number of SCDs, whereas other cardiac disorders, including congenital heart defects and the known genetically determined ion channel anomalies, account for $5-10 \%$ of SCDs (1).

While the implantable cardioverter defibrillator (ICD) improves survival in high-risk patients (2), standard antiarrhythmic drug therapy has failed to reduce, and in some instances has increased, the incidence of SCD (3). In fact, the greatest reduction in cardiovascular mortality (including SCD) in patients with clinically manifest heart disease has resulted from the use of beta blockers (4) and non-antiarrhythmic drugs, i.e., those without major direct electrophysiological action in cardiac muscle or the specialized conduction system, such as angiotensin-converting enzyme (ACE) inhibitors, angiotensin receptor-blocking agents, lipid-lowering agents, spironolactone, thrombolytic and antithrombotic agents, and perhaps magnesium and omega-3 fatty acids (for review, see ref. 5). These drugs most likely exert their antiarrhythmic potential indirectly by inhibiting or delaying adverse functional and structural remodeling in the diseased heart, i.e., by affecting

Nonstandard abbreviations used: ACE, angiotensin-converting enzyme; $\left[\mathrm{Ca}^{2+}\right]_{i}$, intracellular $\mathrm{Ca}^{2+}$ concentration; CASQ2, calsequestrin 2; CPVT, catecholaminergic polymorphic VT; DAD, delayed after-depolarization; EAD, early after-depolarization; FKBP12.6, 12.6-kDa FK506-binding protein; $\mathrm{I}_{\mathrm{Ca} . \mathrm{L}}, \mathrm{L}$-type $\mathrm{Ca}^{2+}$ current; ICD, implantable cardioverter defibrillator; $\mathrm{I}_{\mathrm{Na} / \mathrm{Ca}}, \mathrm{Na}^{+} / \mathrm{Ca}^{2+}$ exchange current; $\mathrm{IP}_{3}$, inositol-1,4,5 triphosphate; $\mathrm{I}_{\text {to }}$, transient outward $\mathrm{K}^{+}$current; LQTS, long-QT syndrome; $\left[\mathrm{Na}^{+}\right]_{\mathrm{i}}$, intracellular $\mathrm{Na}^{+}$concentration; RAS, renin-angiotensin system; RyR2, ryanodine receptor 2; SCD, sudden cardiac death; SR, sarcoplasmic reticulum; VF, ventricular fibrillation; $V_{\mathrm{m}}$, membrane potential; VT, ventricular tachycardia.

Conflict of interest: The authors have declared that no conflict of interest exists.

Citation for this article: J. Clin. Invest. 115:2305-2315 (2005).

doi:10.1172/JCI26381. "upstream events" that contribute to the development of electrophysiological instability.

Clinical trials, in general, have failed to define SCD risk markers for specific individuals in the larger general population, where the relative risk of SCD is low but the absolute number of deaths is high. Risk markers include abnormalities in cardiovascular function (left-ventricular ejection fraction), electrocardiographic variables (e.g., late potentials, T-wave alternans, QRS duration, dispersion of repolarization), results of electrophysiological testing (programmed electrical stimulation), and measures of cardiac autonomic function (heart rate at rest and during exercise, heart rate variability, and baroreflex sensitivity), as well as ambient ventricular arrhythmias (premature ventricular depolarizations, nonsustained and sustained VT).

Acquired functional and structural changes occurring in the diseased heart as well as genetic factors (e.g., mutations of ion channel-encoding genes, polymorphism of coagulation factors or $\beta$-adrenergic receptors) may contribute to an increased risk of dying suddenly, but these factors alone cannot explain the apparent randomness of the occurrence of fatal arrhythmias. The nature of the immediate precipitating event that triggers the fatal ventricular tachyarrhythmia at a specific time in an otherwise stable patient remains as the major unanswered question. Better understanding of the interaction among various functional, structural, and genetic factors that are thought to underlie the susceptibility to, and initiation of, fatal arrhythmias is the major goal of future research and should provide new tools for their prediction, prevention, and therapy. This review will highlight the role of some of these factors, with a focus on altered intracellular $\mathrm{Ca}^{2+}$ dynamics, acute myocardial ischemia, neurohumoral changes, and, briefly, genetic predisposition. Additional mechanisms as well as therapeutic and diagnostic approaches are discussed in other recently published review articles (6-9).

\section{The normal electrocardiogram and its relation to the transmembrane action potential and activities of cardiac ion channels}

Both the anatomy and physiology of the specialized conduction system and working cardiac muscle determine how the heart is activated. One cycle of a normal ECG is shown in Figure 1A. The $\mathrm{P}$ wave is produced by the electrical activation of the atria, and the PR interval represents the duration of conduction from the sinus node, through the atria to the ventricles; the QRS complex is generated by electrical activation of the ventricles; 


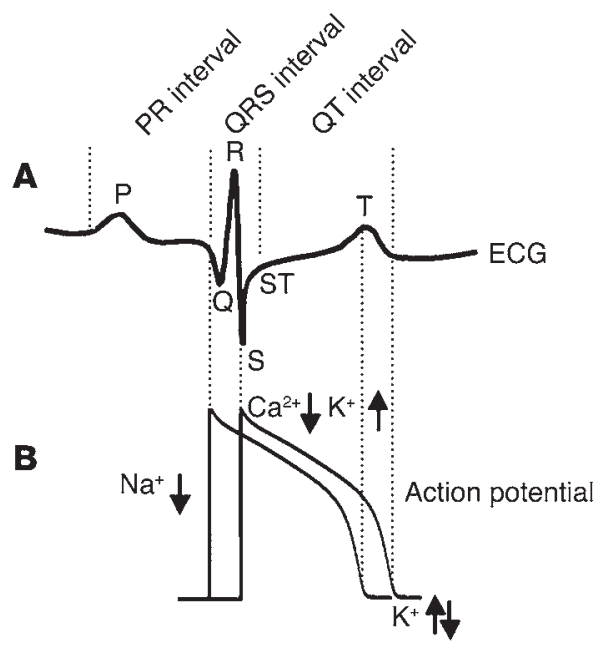

and the ST-T wave reflects recovery. During a normal cardiac cycle, electrical excitation starts in the sinus node, then moves to the atria, crossing the atrioventricular node and His bundle, and finally reaches the ventricles. The QRS complex reflects the sum of the spatial patterns of ventricular activation. Ventricular excitation rapidly spreads along the specialized intracardiac conduction system (His-Purkinje system) in the endocardium, resulting in depolarization of most of the endocardial surfaces of both ventricles within several milliseconds. The activation front then moves from endocardium to epicardium, starting at the Purkinje-muscle cell junctions and proceeding by cell-to-cell conduction through the muscle toward the epicardium. Ventricular recovery, like activation, occurs in a stereotypical geometrical pattern. Differences in recovery timing occur both across the ventricular wall and between regions of the left and right ventricles and give rise to the characteristic morphology of the ST-T wave in the electrocardiogram.

Transmembrane ionic currents are ultimately responsible for the electrical activity recorded in the ECG. Shown in Figure 1B are the major ion fluxes during a normal ventricular action potential. Initial $\mathrm{Na}^{+}$influx through open $\mathrm{Na}^{+}$channels causes rapid membrane depolarization, which in turn activates $\mathrm{Ca}^{2+}$ channels. The ensuing inflow of $\mathrm{Ca}^{2+}$ causes $\mathrm{Ca}^{2+}$ release channels in the sarcoplasmic reticulum (SR) membrane to open, increasing the cytosolic calcium level and causing contraction. Finally, an increase in $\mathrm{K}^{+}$efflux through activated $\mathrm{K}^{+}$channels restores the resting membrane potential $\left(\mathrm{V}_{\mathrm{m}}\right.$; repolarization), and removal of $\mathrm{Ca}^{2+}$ from the cytosol deactivates contractile proteins, thereby relaxing the cardiac muscle.

\section{Figure 1}

Temporal relationship between ECG and single cardiomyocyte action potential. (A) The waves and intervals of a normal ECG. (B) Schematic representation of a ventricular action potential and its major underlying ionic currents. The downward arrow indicates influx; the upward arrow, efflux.

\section{The emerging role of altered intracellular $\mathrm{Ca}^{2+}$ dynamics in cardiac arrhythmogenesis}

Alterations in intracellular calcium homeostasis play an important role in the development of ventricular tachyarrhythmias in the failing heart (10), as well as in some inherited syndromes leading to SCD. Congenital $\mathrm{Ca}^{2+}$ handling anomalies in the heart include defective function of the ryanodine receptor 2 (RyR2) in catecholaminergic polymorphic VT (CPVT) (11); a loss-of-function mutation in ankyrin-B causing type 4 long-QT cardiac arrhythmias (12); and a missense mutation of calsequestrin 2 (CASQ2) causing stress-induced polymorphic VT (13). Disruption of the gene encoding the 12.6-kDa FK506-binding protein (FKBP12.6), which reversibly associates with and modulates the activity of RyR2, causes similar alterations in intracellular $\mathrm{Ca}^{2+}$ signaling in cardiomyocytes of male and female mice but results in hypertrophy in male mice only (14). It is currently not known whether similar gen-

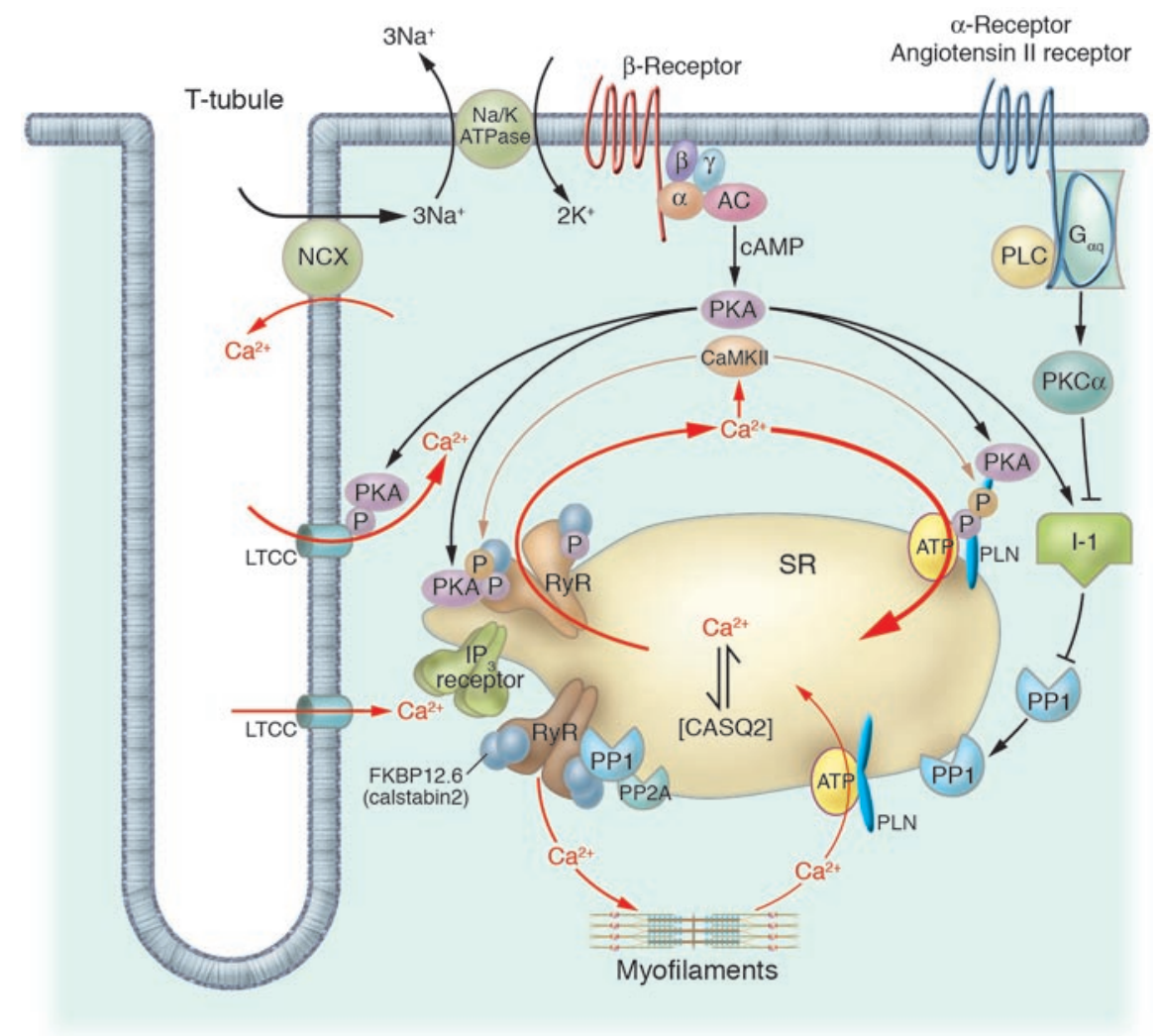

Figure 2

Schematic illustration of intracellular $\mathrm{Ca}^{2+}$ cycling and associated second messenger pathways in cardiomyocytes (figure modified from ref. 84). AC, adenylyl cyclase; $\alpha$, G protein subunit $\alpha ; \alpha$-receptor, $\alpha$-adrenergic receptor; $\beta$, G protein subunit $\beta ; \beta$-receptor, $\beta$-adrenergic receptor; $\gamma$, G protein subunit $\gamma$; LTCC, L-type $\mathrm{Ca}^{2+}$ channel; CAMKII, $\mathrm{Ca}^{2+}$-calmodulin kinase II; I-1, inhibitor 1; $\mathrm{NCX}, \mathrm{Na}^{+} / \mathrm{Ca}^{2+}$ exchanger; P, phosphate group; PLC, phospholipase C; PLN, phospholamban; PP1, protein phosphatase 1; PP2A, protein phosphatase 2A; SERCA2a, SR $\mathrm{Ca}^{2+-}$ ATPase isoform 2a; T-tubule, transverse tubule. 
A

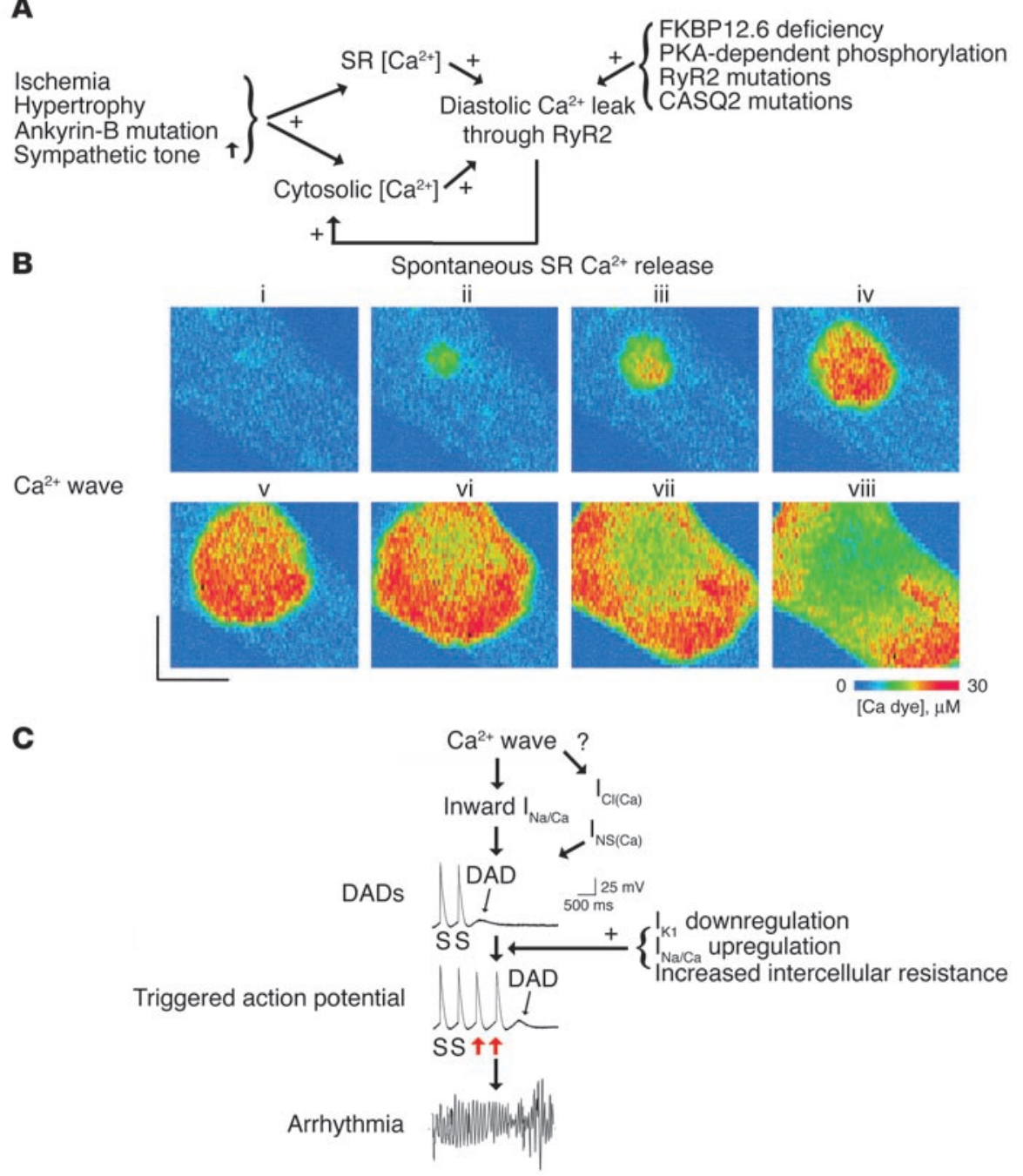

\section{Figure 3}

Proposed scheme of events leading to DADs and triggered tachyarrhythmia. (A) Congenital (e.g., ankyrin-B mutation) and/or acquired factors (e.g., ischemia, hypertrophy, increased sympathetic tone) will cause a diastolic $\mathrm{Ca}^{2+}$ leak through RyR2, resulting in localized and transient increases in $\left[\mathrm{Ca}^{2+}\right]_{\mathrm{i}}$ in cardiomyocytes. (B) Representative series of images showing changes in $\left[\mathrm{Ca}^{2+}\right]_{i}$ during a $\mathrm{Ca}^{2+}$ wave in a single cardiomyocyte loaded with a $\mathrm{Ca}^{2+}$-sensitive fluorescent dye. Images were obtained at 117-ms intervals. Focally elevated $\mathrm{Ca}^{2+}$ (ii) diffuses to adjacent junctional SR, where it initiates more $\mathrm{Ca}^{2+}$ release events, resulting in a propagating $\mathrm{Ca}^{2+}$ wave (iii-viii). Reproduced with permission from Biophysical Journal (85). (C) The $\mathrm{Ca}^{2+}$ wave, through activation of $\mathrm{Ca}^{2+}$-sensitive inward currents, will depolarize the cardiomyocyte (DAD). In cardiomyocytes, the inward $I_{\mathrm{Na} / \mathrm{Ca}}$ is the major candidate for the transient inward current underlying DADs, although the role of the $\mathrm{Ca}^{2+}$-activated $\mathrm{Cl}^{-}$current $\left[\mathrm{I}_{\mathrm{Cl}(\mathrm{Ca})}\right]$ and a $\mathrm{Ca}^{2+}$-sensitive nonspecific cation current $\left[I_{\mathrm{NS}(\mathrm{Ca})}\right]$ cannot be excluded. If of sufficient magnitude, the DAD will depolarize the cardiomyocyte above threshold resulting in a single or repetitive premature heartbeat (red arrows), which can trigger an arrhythmia. Downregulation of the inward rectifier potassium current $\left(\mathrm{I}_{\mathrm{K} 1}\right)$, upregulation of $\mathrm{I}_{\mathrm{Na} / \mathrm{Ca}}$, or a slight increase in intercellular electrical resistance can promote the generation of DAD-triggered action potentials. S, stimulus. Modified with permission from Circulation Research (26) and Nature (12). der differences exist for the susceptibility to arrhythmias in hearts exhibiting inherited disorders of $\mathrm{Ca}^{2+}$ handling proteins.

Cardiac arrbythmogenesis associated with RyR2 dysfunction in CPVT and heart failure. RyR2 is the major $\mathrm{Ca}^{2+}$ release channel required for excitation-contraction coupling in cardiomyocytes. Depolarization of the cardiomyocyte cell membrane causes $\mathrm{Ca}^{2+}$ influx through activated voltage-dependent L-type $\mathrm{Ca}^{2+}$ channels, which in turn initiates $\mathrm{Ca}^{2+}$ release via RyR2s from the SR (Figure 2), known as $\mathrm{Ca}^{2+}$-induced $\mathrm{Ca}^{2+}$ release (15). RyR2-mediated $\mathrm{Ca}^{2+}$ release activates contractile proteins, which results in cardiac contraction during systole. During diastole, cytosolic $\mathrm{Ca}^{2+}$ re-sequesters into the SR via the phospholamban-regulated SR $\mathrm{Ca}^{2+}$-ATPase isoform 2a (SERCA2a); binding of FKBP12.6 (also known as calstabin2) to the RyR2 complex maintains the channel in a closed state to prevent leakage of $\mathrm{SR} \mathrm{Ca}^{2+}$ into the cytoplasm. Phosphorylation of RyR2s by PKA during adrenergic stimulation (e.g., exercise) dissociates FKBP12.6 from the RyR2 channel complex, which results in increased RyR2 open probability, defined as the fraction of time the channel is in the open, i.e., conducting, state. RyR2 mutations in patients with CPVT reduce the affinity of the $\mathrm{SR} \mathrm{Ca}^{2+}$ release channel for FKBP12.6, which causes $\mathrm{Ca}^{2+}$ to leak out of the SR during diastole (11). The electrocar- diographic phenotype of clinical CPVT is mimicked in transgenic mice deficient in FKBP12.6 (16). Increasing the binding affinity of FKBP12.6 for the RyR2 complex prevents exercise- and catecholamine-induced polymorphic VT and SCD in FKBP12.6-deficient mice (16). In heart failure, the RyR2 channel-FKBP12.6 complex has been shown to be depleted of FKBP12.6 due to chronic PKAmediated hyperphosphorylation, which results in an abnormal increase in RyR2 open probability during diastole (10).

Whereas these observations provide compelling evidence that abnormalities in intracellular $\mathrm{Ca}^{2+}$ homeostasis play a primary role in causing SCD due to cardiac arrhythmias, the mechanism by which spontaneous $\mathrm{Ca}^{2+}$ release from the SR can trigger fatal arrhythmias has remained elusive.

Congenital and/or acquired factors can cause a diastolic $\mathrm{Ca}^{2+}$ leak through RyR2 (Figure 3A), giving rise to localized increases in cytosolic calcium (Figure 3B, ii) in a single cardiomyocyte loaded with a $\mathrm{Ca}^{2+}$-sensitive fluorescent dye. The focally elevated $\mathrm{Ca}^{2+}$ then diffuses to adjacent junctional SR to activate $\mathrm{Ca}^{2+}$ release channels and induce release of $\mathrm{Ca}^{2+}$ that can then propagate throughout the cell. This regenerative propagating process has previously been termed a $\mathrm{Ca}^{2+}$ wave (17). Diastolic $\mathrm{Ca}^{2+}$ waves depolarize the cardiomyocyte membrane, triggering a delayed after-depolarization 
(DAD) via transient activation of a $\mathrm{Ca}^{2+}$-dependent inward current (18) (Figure 3C). Candidates for the transient inward current are the electrogenic $\mathrm{Na}^{+} / \mathrm{Ca}^{2+}$ exchange current $\left(\mathrm{I}_{\mathrm{Na} / \mathrm{Ca}}\right)$ operating in its forward mode (extruding $\mathrm{Ca}^{2+}$ and taking up $\mathrm{Na}^{+}$in a $1: 3$ stoichiometry); the $\mathrm{Ca}^{2+}$-activated $\mathrm{Cl}^{-}$current $\left(\mathrm{I}_{\mathrm{Cl}(\mathrm{Ca})}\right)$; and a Ca ${ }^{2+}$-activated nonselective cation current $\left(\mathrm{I}_{\mathrm{NS}(\mathrm{Ca})}\right)$. More recent work has supported a major role of $\mathrm{I}_{\mathrm{Na} / \mathrm{Ca}}$ in causing DADs in ventricular myocytes, with $\mathrm{I}_{\mathrm{Cl}(\mathrm{Ca})}$ and $\mathrm{I}_{\mathrm{NS}(\mathrm{Ca})}$ contributing only a little or not at all to DAD initiation (18).

Only when spontaneous $\mathrm{Ca}^{2+}$ release events occur at multiple sites synchronously within the cell will their spatial and temporal summation result in a rise in intracellular $\mathrm{Ca}^{2+}$ concentration $\left(\left[\mathrm{Ca}^{2+}\right]_{\mathrm{i}}\right)$ of sufficient magnitude to trigger an action potential. Increases in $\left[\mathrm{Ca}^{2+}\right]_{\mathrm{i}}$ exceeding $1 \mu \mathrm{mol} / 1$ are required for action potential activation in isolated ventricular cardiomyocytes (18), which can then propagate throughout the ventricles to induce an extra heartbeat, leading to VT and VF (Figure 3C). While factors determining whether a DAD triggers an action potential in isolated cardiomyocytes have been characterized, what determines whether a DAD produces a propagating action potential in the intact myocardium is less well known.

In the intact heart, the change in $V_{m}$ in response to a given increase in inward current activated by the local increase in $\left[\mathrm{Ca}^{2+}\right]_{i}$ is usually less than that in an isolated cardiomyocyte because more passive outward current opposes the depolarizing effect of locally activated $\mathrm{Na}^{+}$channel current in cardiac tissue. Individual cardiomyocytes are electrically coupled to their neighbors, as opposed to isolated cardiomyocytes, which are disconnected. Therefore, to induce membrane depolarization in a sufficient number of cardiomyocytes simultaneously to effectively increase the current load, action potential initiation from a DAD in the whole heart would probably require that spontaneous $\mathrm{Ca}^{2+}$ waves occur almost synchronously in multiple, closely adjacent cardiomyocytes or that a single $\mathrm{Ca}^{2+}$ wave rapidly propagate across cell borders. However, $\mathrm{Ca}^{2+}$ waves in intact cardiac preparations rarely spread to their neighboring cells under physiological conditions and do not appear to occur synchronously in multiple contiguous cardiomyocytes $(17,19,20)$. Electrophysiological changes occurring in the failing heart, such as doubling of $\mathrm{Na}^{+} / \mathrm{Ca}^{2+}$ exchanger expression and reduction in repolarizing $\mathrm{K}^{+}$currents (18), could facilitate action potential initiation from a DAD (6). Thus, for any given increase in $\left[\mathrm{Ca}^{2+}\right]_{\mathrm{i}}$, the inward current carried by the $\mathrm{Na}^{+} / \mathrm{Ca}^{2+}$ exchanger will be doubled, and the reduction of outwardly directed $\mathrm{K}^{+}$currents will enhance the depolarizing effect of a given $\mathrm{I}_{\mathrm{Na} / \mathrm{Ca}}$. Furthermore, reduced intercellular electrical coupling in nonischemic failing myocardium (21) and redistribution of gap junctions between cardiomyocytes in the epicardial border zone of chronic infarcts (22) may blunt electrotonic interactions between DAD-generating cardiomyocytes and their neighbors, reducing the inward current required to depolarize the cardiomyocytes above threshold. However, an increase in intercellular resistance may prevent the propagation of triggered action potentials. Finally, increased adrenergic activation in failing myocardium leads to SR $\mathrm{Ca}^{2+}$ overload, resulting in enhanced activity of RyR 2 channels during diastole (23) and the enhanced probability of $\mathrm{Ca}^{2+}$ wave occurrence.

Collectively, these results strongly suggest that defective RyR2 gating and associated aberrant $\mathrm{Ca}^{2+}$ release from the SR during diastole may constitute the molecular trigger for arrhythmia initiation in the failing heart (Figure 3).
Three-dimensional mapping studies in intact hearts support the hypothesis that spontaneous SR $\mathrm{Ca}^{2+}$ release events act as focal triggers of arrhythmias by showing that nearly all VT in nonischemic heart failure and approximately $50 \%$ of those in ischemic heart failure arise from abnormal automaticity (ectopic pacemaker firing at a rate greater than the sinus node rate) or triggered activity, such as DADs and early after-depolarizations (EADs) (24-26). However, optical mapping studies in isolated perfused left-ventricular wedge preparations have revealed that electrical reentry was the primary mechanism responsible for VT during acute myocardial ischemia $(27,28)$. Reentrant excitation can occur when myocardium not activated during a preceding wave of depolarization recovers excitability in time to be discharged before the impulse dies out.

Ankyrin-B mutation in long-QT4 syndrome. A loss-of-function mutation in ankyrin-B (also known as ankyrin 2), a member of a family of membrane adaptor proteins, causes type 4 long-QT syndrome (LQTS) cardiac arrhythmias and SCD (12). The congenital LQTS is characterized by prolongation of the QT interval (see Figure 1), recurrent syncope, and life-threatening VT/VF. In addition to the mutation in the gene encoding ankyrin-B, loss- or gain-of-function mutations in a number of different ion channel-encoding genes, including cardiac $\mathrm{Na}^{+}$and $\mathrm{K}^{+}$channel genes, have been identified in inherited LQTS. Ankyrin-B is the first protein to be implicated in LQTS that is not an ion channel or auxiliary ion channel subunit.

Transgenic mice heterozygous for the ankyrin-B mutation, which results in substitution of glycine for a glutamic acid at amino acid residue 1425 (E1425G), exhibit a cardiac phenotype that is very similar to that seen in type 4 LQTS patients, including QT prolongation, intermittent sinus bradycardia, and SCD from stress-induced polymorphic VT (see Figure 3C) (12). Ankyrin-B mutations disrupt the cellular organization of ankyrin-B binding partners in cardiomyocytes, including the $\mathrm{Na}^{+} / \mathrm{Ca}^{2+}$ exchanger, the $\mathrm{Na}^{+} / \mathrm{K}^{+}$ATPase (an electrogenic pump in the outer membrane extruding $\mathrm{Na}^{+}$ions and taking up $\mathrm{K}^{+}$ions in a 3:2 stoichiometry), and the inositol-1,4,5 triphosphate $\left(\mathrm{IP}_{3}\right)$ receptor $\left(\mathrm{a} \mathrm{Ca}^{2+}\right.$ release channel in the SR that is activated by binding of $\mathrm{IP}_{3}$ ), resulting in reduced targeting of these proteins to the transverse tubules (Figure 2) as well as reducing their overall expression levels. Peak amplitudes of depolarization-induced $\left[\mathrm{Ca}^{2+}\right]_{\mathrm{i}}$ transients are markedly increased in single cardiomyocytes isolated from heterozygous ankyrin-B mutant $\left(A n k B^{+/-}\right)$mice. It is conceivable that reduced activity of the $\mathrm{Na}^{+} / \mathrm{K}^{+}$ATPase increases intracellular $\mathrm{Na}^{+}$concentration $\left(\left[\mathrm{Na}^{+}\right]_{\mathrm{i}}\right)$, which in turn inhibits $\mathrm{Ca}^{2+}$ extrusion by the $\mathrm{Na}^{+} / \mathrm{Ca}^{2+}$ exchanger into the extracellular space (see Figure 2). As $\mathrm{Na}^{+} / \mathrm{Ca}^{2+}$ exchanger expression is reduced, total cellular $\mathrm{Ca}^{2+}$ content becomes elevated. Cellular $\mathrm{Ca}^{2+}$ overload can lead to increased incidence of DAD-generating $\mathrm{Ca}^{2+}$ waves. Transmembrane potential recordings in single $A n k B^{+/-}$cardiomyocytes during $\beta$-adrenergic receptor activation revealed extrasystoles arising from DADs as well as from EADs (12), which suggests that these mechanisms are responsible for at least some of the VT/VF in LQTS patients.

Whereas it is generally accepted that DADs are initiated by spontaneous $\mathrm{Ca}^{2+}$ release from the $\mathrm{SR}$, the involvement of $\mathrm{SR} \mathrm{Ca}^{2+}$ release in the generation of EADs occurring in the plateau phase of the action potential is controversial. Some EADs are attributable to recovery from inactivation and reactivation of voltage-dependent L-type $\mathrm{Ca}^{2+}$ channels during prolonged action potentials, while EADs occurring late during repolarization may arise from 
spontaneous SR $\mathrm{Ca}^{2+}$ release and transient activation of a depolarizing inward current. The role of $\mathrm{Ca}^{2+}$ handling in the initiation of EADs and polymorphic VT (torsade de pointes [TdP]) has recently been studied by the simultaneously mapping of $V_{m}$ and $\left[\mathrm{Ca}^{2+}\right]_{\mathrm{i}}$ in an animal model of type 2 LQTS (29). It was shown that at the sites of origin of EADs, increases in $\left[\mathrm{Ca}^{2+}\right]_{\mathrm{i}}$ preceded membrane depolarization, whereas away from these sites, increases in $\left[\mathrm{Ca}^{2+}\right]_{i}$ coincided with or followed membrane depolarization. Conceivably, spontaneous $\mathrm{Ca}^{2+}$ release from internal stores activates inward currents to generate an EAD and a propagated action potential. Ischemia can enhance the development of EADs under some circumstances (30).

CASQ2 mutation in CPVT. A missense mutation in the gene encoding CASQ2, a $\mathrm{Ca}^{2+}$-binding protein in the cardiac luminal $\mathrm{SR}$, causes the recessive form of CPVT. Sequence analyses of the CASQ2 genes of CPVT patients revealed substitution of histidine for an aspartic acid at amino acid residue 307 (D307H). Simultaneous recordings of $\mathrm{V}_{\mathrm{m}}$ and $\left[\mathrm{Ca}^{2+}\right]_{\mathrm{i}}$ in single cardiomyocytes with adenovirus-mediated expression of CASQ2 carrying the CPVTlinked mutation $\mathrm{D} 307 \mathrm{H}\left(\mathrm{CASQ} 2^{\mathrm{D} 307 \mathrm{H}}\right)$ revealed $\mathrm{Ca}^{2+}$ waves and associated DADs during rapid pacing and $\beta$-adrenergic receptor stimulation (13). Primary alterations in cellular $\mathrm{Ca}^{2+}$ homeostasis, similar to those underlying CPVT and long-QT4 arrhythmias, could constitute the trigger for these arrhythmogenic events.

$S R \mathrm{Ca}^{2+}$ cycling in VF and electrical alternans. At normal heart rates, $\left[\mathrm{Ca}^{2+}\right]_{\mathrm{i}}$ reliably and consistently tracks changes in $\mathrm{V}_{\mathrm{m}}$. Mapping studies have demonstrated that $\mathrm{SR} \mathrm{Ca}^{2+}$ cycling may exhibit intrinsic dynamics and may become independent of changes in $\mathrm{V}_{\mathrm{m}}$ during VF. Non-voltage-gated SR $\mathrm{Ca}^{2+}$ release events, through modulation of $\mathrm{Ca}^{2+}$-sensitive membrane currents, then cause local alterations in action potential duration and myocardial refractoriness, which in turn promote the maintenance of fibrillatory activity (31). Thus, spatial heterogeneity of $\left[\mathrm{Ca}^{2+}\right]_{i}$ signaling may act not only as a trigger but also as a stabilizer of VT/VF.

Beat-to-beat variations in T-wave morphology and/or polarity (T-wave alternans), a marker of increased electrical instability and fibrillation (32), arise from alternation in action potential duration. Simultaneous measurements of $\left[\mathrm{Ca}^{2+}\right]_{i}$ and $V_{m}$ in single cardiomyocytes as well as in whole hearts during rapid pacing provide evidence that primary alternans in the amplitude and duration of $\left[\mathrm{Ca}^{2+}\right]_{\mathrm{i}}$ transients can drive action potential duration to alternate secondarily, by influencing several key membrane currents that are sensitive to changes in $\left[\mathrm{Ca}^{2+}\right]_{i}(33-35)$.

Collectively, these observations support the concept that SR $\mathrm{Ca}^{2+}$ cycling plays an important role in contributing to action potential dynamics during VT/VF.

Intracellular calcium regulates second messenger pathways and ion channel gene transcription. Intracellular $\mathrm{Ca}^{2+}$ ions influence the activity of ion channels and/or transporters via direct interaction with the ion-conducting molecule and indirectly via modulation of $\mathrm{Ca}^{2+}$ sensitive intracellular signaling pathways. $\mathrm{Ca}^{2+}$ can directly bind to a subunit of the voltage-dependent $\mathrm{Na}^{+}$channel, which results in altered $\mathrm{Na}^{+}$channel gating (36). $\mathrm{Ca}^{2+}$ also activates $\mathrm{Ca}^{2+}$-calmodulin kinase II (CaMKII) (see Figure 2), which in turn targets key molecules that control intracellular $\mathrm{Ca}^{2+}$ homeostasis in cardiomyocytes, and increased CaMKII activity may trigger arrhythmia-initiating after-depolarizations by activating L-type $\mathrm{Ca}^{2+}$ channels or increasing inward current carried by the $\mathrm{Na}^{+} / \mathrm{Ca}^{2+}$ exchanger $(37,38)$. Determining whether alterations in the sensitivity of the target molecules to changes in intracellular $\mathrm{Ca}^{2+}$ levels and/or alterations in intracellular second messenger signaling cascades contribute to arrhythmogenesis in conditions of abnormal intracellular $\mathrm{Ca}^{2+}$ handling will be important.

Collectively, these studies highlight the fundamental importance of investigating the spatial and temporal relationship of membrane voltage and intracellular $\mathrm{Ca}^{2+}$ dynamics in the whole heart. Techniques for simultaneously mapping transmembrane voltage and $\left[\mathrm{Ca}^{2+}\right]_{i}$ with high temporal resolution in the intact heart have recently been developed (29) and will provide novel insights into the factors that facilitate the development of DAD- or EAD-related non-reentrant arrhythmias as well as the role of $\left[\mathrm{Ca}^{2+}\right]_{i}$ in reentrant arrhythmias in animal models of SCD.

In addition to the transient effects of increased $\left[\mathrm{Ca}^{2+}\right]_{\mathrm{i}}$ on cardiomyocyte excitability, chronic changes in $\left[\mathrm{Ca}^{2+}\right]_{i}$ in the regulation of ion channel expression in cardiomyocytes can effect lasting alterations in electrical properties (39). For example, long-term changes in intracellular $\mathrm{Ca}^{2+}$ handling in transgenic mice overexpressing SERCA1a caused downregulation of $\mathrm{K}^{+}$channel expression in the absence of cardiac hypertrophy and failure, leading to action potential prolongation (39). Determining the molecular underpinnings of these remodeling processes will potentially create novel targets for antiarrhythmic prevention.

\section{Acute myocardial ischemia}

Ionic imbalances during acute myocardial ischemia. Many SCDs from VT/VF occur during acute myocardial ischemia (40). Abrupt cessation of myocardial blood flow causes redistribution of a number of ions, including $\mathrm{H}^{+}, \mathrm{Na}^{+}, \mathrm{Ca}^{2+}$, and $\mathrm{K}^{+}$, across the cardiomyocyte membrane, an event that has profound electrophysiological consequences through its influence on the activity of a variety of ion channels and transporters. However, the details of their interactions vis-à-vis initiation of the triggering premature beat and maintenance of arrhythmias have remained largely elusive.

Net cellular $\mathrm{K}^{+}$loss and subsequent extracellular $\mathrm{K}^{+}$accumulation during acute myocardial hypoxia and/or ischemia causes sustained membrane depolarization that leads to a slowing of conduction and altered refractoriness, which in combination with other factors promote VT/VF and SCD $(27,28)$. Despite the fact that $\mathrm{K}^{+}$loss is an important pathogenic factor in ischemia-associated arrhythmogenesis, the underlying mechanisms are not completely understood. Net $\mathrm{K}^{+}$loss in part reflects passive intracellular $\mathrm{Na}^{+}$gain during myocardial hypoxia/ischemia (41). Net intracellular $\mathrm{Na}^{+}$gain implies that the $\mathrm{Na}^{+} / \mathrm{K}^{+}$ATPase is unable to compensate for the amount of $\mathrm{Na}^{+}$ions entering the cardiomyocytes through the major $\mathrm{Na}^{+}$ influx pathways, including voltage-gated $\mathrm{Na}^{+}$channels, $\mathrm{Na}^{+} / \mathrm{Ca}^{2+}$ exchanger, $\mathrm{Na}^{+} / \mathrm{H}^{+}$exchanger, and potentially plasmalemmal connexin-43 hemichannels (42) (Figure 4). It is unknown whether the influx/efflux mismatch results from a primary increase in $\mathrm{Na}^{+}$ uptake rate beyond the maximal $\mathrm{Na}^{+} / \mathrm{K}^{+}$ATPase pump capacity, primary inhibition of the pump, or both. Ischemia-induced decrease in intracellular ATP content may inhibit $\mathrm{Na}^{+} / \mathrm{K}^{+}$ATPase. Increased intracellular proton generation increases $\mathrm{Na}^{+}$influx via increased activity of the $\mathrm{Na}^{+} / \mathrm{H}^{+}$exchanger. Build-up of the ischemic metabolite lysophosphatidylcholine enhances $\mathrm{Na}^{+}$influx through voltage-dependent, tetrodotoxin-sensitive $\mathrm{Na}^{+}$channels (43). Major $\mathrm{K}^{+}$efflux pathways during hypoxia/ischemia involve ATP-dependent $\mathrm{K}^{+}$channels, inward rectifier $\mathrm{K}^{+}$channels, as well as other voltage-gated $\mathrm{K}^{+}$channels, and potentially connexin- 43 hemichannels (42). Net cellular $\mathrm{K}^{+}$loss is thought to maintain electroneutrality of charge movement and cellular osmolarity. Increases in $\left[\mathrm{Na}^{+}\right]_{\mathrm{i}}$ 


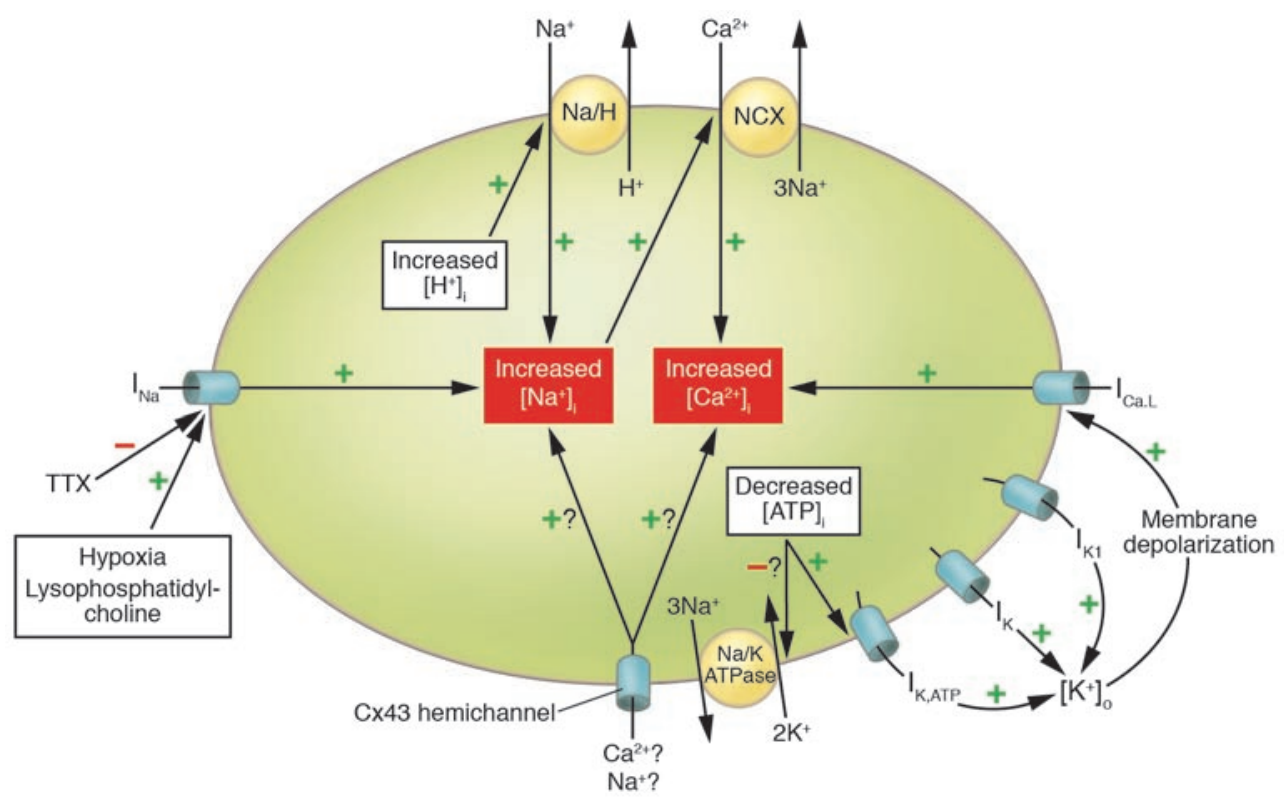

Figure 4

Proposed scheme of events leading to transmembrane ionic imbalances during myocardial ischemia. Net intracellular $\mathrm{Na}^{+}$gain due to a mismatch of $\mathrm{Na}^{+}$influx and efflux will cause net cellular $\mathrm{K}^{+}$loss, extracellular $\mathrm{K}^{+}$accumulation, and an increase in intracellular $\mathrm{Ca}^{2+}$ due to activation of the $\mathrm{Na}^{+} / \mathrm{Ca}^{2+}$ exchanger operating in the reverse mode. Cellular $\mathrm{Ca}^{2+}$ overload will cause triggered arrhythmias by the mechanisms illustrated in Figure 3. Lysophosphatidylcholine is a product of diacyl phospholipid catabolism generated by the enzyme phospholipase A2 during ischemia. Question marks indicate that the pathway/mechanism is hypothetical. $[\text { ATP }]_{\mathrm{i}}$, intracellular concentration of adenosine triphosphate; $\mathrm{Cx} 43$, connexin- 43 ; $\left[\mathrm{H}^{+}\right]$, intracellular proton concentration; $I_{\mathrm{K}}$, delayed rectifier $\mathrm{K}^{+}$current; $\mathrm{I}_{\mathrm{K}, \mathrm{ATP}}$, ATP-sensitive potassium current; $\mathrm{I}_{\mathrm{K} 1}$, inward rectifier $\mathrm{K}^{+}$ current; I $\mathrm{I}_{\mathrm{Na}}$, fast $\mathrm{Na}^{+}$current; $\mathrm{Na} / \mathrm{H}$, sodium-hydrogen exchanger; $\left[\mathrm{K}^{+}\right]_{\mathrm{o}}$, extracellular $\mathrm{K}^{+}$concentration; TTX, tetrodotoxin (a specific blocker of the fast sodium current).

may have detrimental electrophysiological effects. $\left[\mathrm{Na}^{+}\right]_{\mathrm{i}}$ regulates cardiac $\left[\mathrm{Ca}^{2+}\right]_{i}$. An increase in $\left[\mathrm{Na}^{+}\right]_{\mathrm{i}}$ will result in an increase in $\left[\mathrm{Ca}^{2+}\right]$, due to an increase in $\mathrm{Ca}^{2+}$ influx via the $\mathrm{Na}^{+} / \mathrm{Ca}^{2+}$ exchanger operating in the reverse mode and depolarization-activated L-type $\mathrm{Ca}^{2+}$ channels, and possibly direct $\mathrm{Ca}^{2+}$ influx through connexin-43 hemichannels (42) (Figure 4).

Role of intracellular calcium in ischemia-associated arrbythmias. Cellular $\mathrm{Ca}^{2+}$ overload secondary to $\mathrm{Na}^{+}$overload can increase the probability that DAD-generating $\mathrm{Ca}^{2+}$ waves will be induced. While the relationship between the amount of $\mathrm{Ca}^{2+}$ released from internal stores during a wave and the magnitude of the associated change in $V_{\mathrm{m}}$ has been characterized in isolated cardiomyocytes under normal conditions, it has not been rigorously quantified in partially depolarized cardiomyocytes typically found in the ischemic myocardium. It has also remained unknown whether spontaneous $\mathrm{Ca}^{2+}$ release through ryanodine-insensitive $\mathrm{Ca}^{2+}$ release channels (e.g., $\mathrm{IP}_{3}$ receptors; see Figure 2) contributes to the induction of $\mathrm{Ca}^{2+}$ waves in the setting of acute ischemia and which membrane conductances are involved in the generation of the transient inward current underlying a DAD.

Even more important are the factors that determine whether a DAD results in a propagating action potential in the setting of acute myocardial ischemia. Although spontaneous $\mathrm{Ca}^{2+}$ waves occur in buffer-perfused isolated heart preparations under physiological conditions as well as following injury $(17,19,20,44)$, it is not known whether $\mathrm{Ca}^{2+}$ waves trigger arrhythmias under ischemic conditions. Conceivably, an increase in the electrical resistance between cardiomyocytes in the acutely ischemic myocardium (45) initiates DAD-related extra beats because reduced intercellular coupling would diminish the opposing, i.e., repolarizing, effect of passive outward current generated by neighboring cardiomyocytes. It is also possible that ischemia induces cellular changes that cause either more $\mathrm{Ca}^{2+}$ to be released from internal stores or greater depolarizations for a given increase in $\left[\mathrm{Ca}^{2+}\right]_{i}$, resulting in an increased propensity for triggered arrhythmias. Because intracellular $\mathrm{Na}^{+}$gain, through its secondary effects on cardiac $\left[\mathrm{Ca}^{2+}\right]_{\mathrm{i}}$ and extracellular $\left[\mathrm{K}^{+}\right]$, appears to act as a primary arrhythmogenic factor in the setting of acute ischemia, it will be important to define the spatio-temporal relationships between $\mathrm{V}_{\mathrm{m}}$ and intracellular concentrations of $\mathrm{Na}^{+}$and $\mathrm{Ca}^{2+}$ (and extracellular $\left[\mathrm{K}^{+}\right]$) in animal models of acute ischemiainduced cardiac arrhythmias and SCD by simultaneously mapping transmembrane voltage and ion concentrations.

Although VT/VF occurring during reperfusion can be reproducibly induced in the experimental setting (46), the role of spontaneous reperfusion in triggering SCD from cardiac arrhythmias remains to be defined. The pathogenic mechanism underlying reperfusion arrhythmias is largely unknown, but an increase in $\left[\mathrm{Na}^{+}\right]_{i}$ during ischemia and/or early reperfusion appears to play a major role (47). Intracellular $\mathrm{Na}^{+}$accumulation can then give rise to $\left[\mathrm{Ca}^{2+}\right]_{\mathrm{i}}$ overload, which in turn increases the propensity for DAD-related arrhythmias by the mechanisms described above.

Whereas there is experimental evidence for the role of spontaneous increases in $\left[\mathrm{Ca}^{2+}\right]_{\mathrm{i}}$ in inducing EADs and related ventricular arrhythmias in the nonischemic setting (29), the involvement of EADs in ischemia/reperfusion-induced arrhythmias has yet to be demonstrated experimentally. Other factors predisposing to EADs may have to be present, including action potential prolongation $(30,48)$ or slight reduction of the electrical conductivity between cells (45). Since failing as well as hypertrophic myocardium exhibit both delayed repolarization and increased electrical resistance $(21,22)$, acute ischemia occurring in the electrically remodeled failing heart may indeed give rise to EAD-related ventricular tachyarrhythmias.

Relationship between $V_{m}$ and $\mathrm{SR} \mathrm{Ca}^{2+}$ cycling in the acutely ischemic myocardium. A study utilizing simultaneous recordings of changes in membrane voltage and intracellular calcium recently showed that acute ischemia exerts contrasting effects on the kinetics of $\mathrm{V}_{\mathrm{m}}$ and $\left[\mathrm{Ca}^{2+}\right]_{\mathrm{i}}$ transients (49). Ischemia was associated with marked shortening of action potential duration but significant prolongation of the $\left[\mathrm{Ca}^{2+}\right]_{i}$ transient. Changes in action 


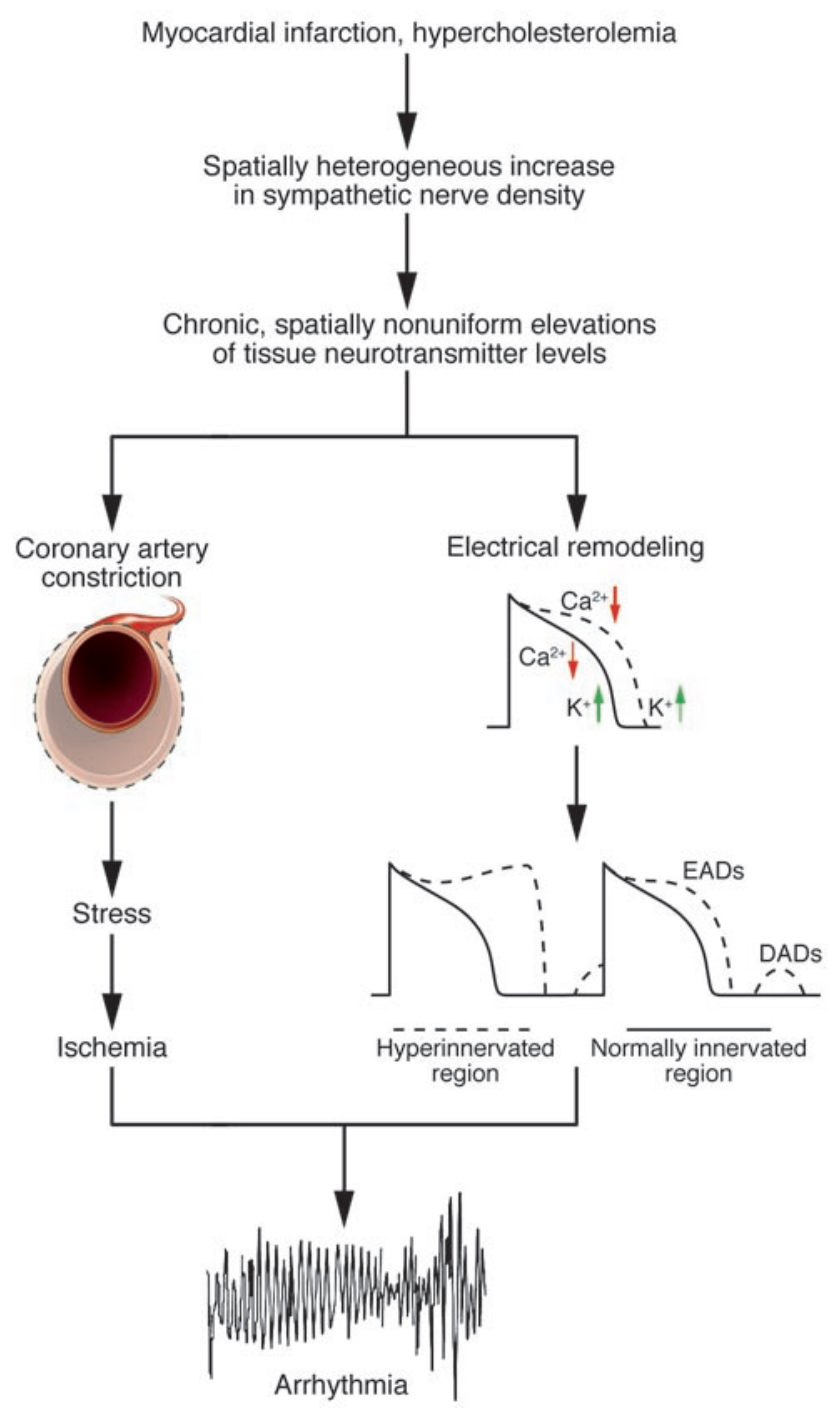

potential duration were spatially more heterogeneous than was lengthening of $\left[\mathrm{Ca}^{2+}\right]_{i}$ transient duration. Moreover, occurrence of $\left[\mathrm{Ca}^{2+}\right]_{\mathrm{i}}$ transient alternans was not consistently associated with alternans of the action potential duration. Thus, in contrast to similar optical mapping studies performed under nonischemic conditions, this study deemphasizes the primary role of alternation of $\left[\mathrm{Ca}^{2+}\right]_{\mathrm{i}}$ transient magnitude and/or duration in determining action potential duration and action potential duration alternans in the setting of acute ischemia.

\section{Neurohumoral changes}

Role of cardiac sympathetic innervation. Activation of cardiac $\beta$-adrenergic receptors by the neurotransmitters epinephrine and norepinephrine has several physiological effects, including increasing systolic contractility and diastolic relaxation rate as well as accelerating heart rate and atrioventricular conduction. At the cardiomyocyte level, stimulation of $\beta$-adrenergic receptors alters the activity of a number of ion channels and transporters via activation of the G protein/adenylyl cyclase/cAMP/PKA pathway (see Figure 2). This in turn results in an increase in both peak amplitude and rate of decline of the $\left[\mathrm{Ca}^{2+}\right]_{i}$ transient via stimulation of key $\mathrm{Ca}^{2+}$ handling proteins as well as shortening of action

\section{Figure 5}

Factors contributing to arrhythmogenesis in hearts with heterogeneous sympathetic innervation. Myocardial injury (e.g., myocardial infarction) or chronic hypercholesterolemia (51) will cause a spatially uneven increase in sympathetic nerve density in the heart, resulting in regional variations in release and, consequently, variations in tissue levels of sympathetic neurotransmitters. Chronic, nonuniform elevations of neurotransmitters, through alterations in the expression of $\mathrm{L}$-type $\mathrm{Ca}^{2+}$ channels and $\mathrm{K}^{+}$channels, create spatial dispersion of action potential duration. Action potential prolongation and augmented $\mathrm{Ca}^{2+}$ influx through L-type $\mathrm{Ca}^{2+}$ channels combine to increase the susceptibility to EAD- and/or DAD-triggered activity in hyperinnervated regions. If the triggered beat propagates throughout the rest of the heart, the preexisting spatial dispersion of action potential duration and, thus, myocardial refractoriness facilitate the initiation of tachyarrhythmias. Locally elevated levels of neuropeptide $Y$ and norepinephrine may increase coronary artery tone, thereby critically reducing the coronary perfusion reserve under conditions of increased oxygen demand (e.g., physical and/or emotional stress) and causing regional ischemia, which contributes to the development of an arrhythmia.

potential duration via augmentation of $\mathrm{K}^{+}$outward currents. The observation that pharmacological beta blockade confers a survival benefit on patients after myocardial infarction suggests an important role of the autonomic nervous system in the pathogenesis of SCD from VT/VF. Further evidence for a neural component in SCD comes from 2 recent experimental studies. In the first study, chronic infusion of nerve growth factor (NGF) to the left stellate ganglion in dogs with chronic myocardial infarction and complete atrioventricular block caused spatially heterogeneous sympathetic cardiac hyperinnervation (nerve sprouting) and dramatically increased the incidence of SCD from VT/VF (50). In a second study, Liu et al. (51) reported that a high-cholesterol diet resulted in myocardial hypertrophy and cardiac sympathetic hyperinnervation in rabbits in the absence of coronary artery stenoses and infarction. Furthermore, they found a marked increase in the incidence of VF, which was associated with enhanced dispersion of repolarization, prolongation of action potential duration and the QT interval, and increased L-type $\mathrm{Ca}^{2+}$ current $\left(\mathrm{I}_{\mathrm{Ca} . \mathrm{L}}\right)$ density (defined as the peak $\mathrm{I}_{\mathrm{Ca} . \mathrm{L}}$ amplitude normalized to the cell surface area). Although results of these studies do not constitute an ultimate proof, they strongly suggest a causal relationship between altered autonomic innervation and SCD due to VT/VF. Intriguingly, explanted human hearts from transplant recipients with a history of arrhythmias exhibited a significantly higher and also more heterogeneous density of sympathetic nerve fibers than those from patients without arrhythmias (52), which indicates that heterogeneous overgrowth of cardiac nerve may occur in human hearts with myocardial infarctions even in the absence of exogenous NGF. Whether neural remodeling also involved parasympathetic nerve fibers in the heart was not examined in these studies.

The precise mechanism by which sympathetic hyperinnervation promotes cardiac arrhythmia is speculative at present. The ultimate manifestation of the arrhythmia is probably the end result of a variety of interacting factors, as schematically illustrated in Figure 5. Increased density of sympathetic nerve endings could augment release of and consequently result in higher than normal tissue concentrations of sympathetic neurotransmitters (e.g., norepinephrine, neuropeptide Y) during sympathetic excitation. This autonomic remodeling is associated with 
spatially heterogeneous electrical remodeling of the cardiomyocytes, including an increase in $\mathrm{I}_{\text {Ca.L }}$ density (51) and decreases in $\mathrm{K}^{+}$current densities (53), resulting in action potential prolongation in hyperinnervated regions (Figure 5). Along with electrical remodeling of a number of ion channels and transporters in the surviving myocardium along the infarct border (i.e., the infarct borer zone), acute release of sympathetic neurotransmitters, through their effects on $\mathrm{Ca}^{2+}, \mathrm{K}^{+}$, and $\mathrm{Cl}^{-}$channels and $\mathrm{Ca}^{2+}$ transporters and enzymes, is likely to accentuate the preexisting heterogeneity of excitability and refractoriness, which in turn is likely to contribute to arrhythmia susceptibility in these models. Norepinephrine- and/or neuropeptide Y-induced arterial constriction can induce myocardial ischemia in hyperinnervated regions during emotional and/or physical stress, further promoting vulnerability to arrhythmic events.

Myocardial ischemia and infarction are known to result in injury of sympathetic nerves and sympathetic denervation of noninfarcted myocardium in areas distal to the infarct (54). Sympathetic denervation potentiates adrenergic responsiveness to catecholamines, a process termed denervation supersensitivity (55). Diffusion of neurotransmitters from normal regions to neighboring denervated areas during sympathetic excitation is likely to create steep local gradients of refractoriness and excitability, further contributing to the arrhythmogenic substrate. Furthermore, superimposed upon prolongation of action potential duration and increased $\mathrm{I}_{\mathrm{Ca.L}}$ density, sympathetic stimulation is likely to lead to intracellular $\mathrm{Ca}^{2+}$ overload, which in turn could give rise to triggered activity, which may underlie the spontaneous occurrence of VF in these animal models.

Future studies on the mechanisms by which neural remodeling contributes to arrhythmia susceptibility will have to address: (a) the molecular and cellular mechanisms regulating sympathetic (and parasympathetic) nerve processing in the normal and diseased heart; (b) the effects (both short- and long-term) of noncholinergic, nonadrenergic neurotransmitters, including neuropeptide $\mathrm{Y}$, calcitonin gene-related product, vasoactive intestinal peptide, and substance $P$, on cardiomyocyte electrophysiology and $\mathrm{Ca}^{2+}$ handling; and (c) the second messenger pathways involved. All 4 peptides have profound physiological effects. Neuropeptide $\mathrm{Y}$, for example, is a potent vasoconstrictor (56) and also appears to be an essential in vivo regulator of cardiac $\mathrm{I}_{\mathrm{Ca} . \mathrm{L}}$ during postnatal development (57). Other questions include the following: what are the altered electrical properties of pre-/postganglionic sympathetic/parasympathetic neurons in the diseased state that result in altered excitation-secretion coupling? what are the mechanisms underlying sympathetically induced ventricular tachyarrhythmias in animal models of SCD? does sympathetic nerve stimulation acutely exaggerate any preexisting electrical heterogeneity in the diseased heart? and, finally, does sympathetic stimulation increase the incidence of abnormalities in intracellular $\mathrm{Ca}^{2+}$ handling in the whole heart $\left(\mathrm{Ca}^{2+}\right.$ waves, beat-to-beat variations in $\mathrm{Ca}^{2+}$ amplitude and/or duration [alternans]) that may act as triggers of ventricular arrhythmias? To answer the latter question, optical mapping techniques will be required to simultaneously measure membrane voltage and $\left[\mathrm{Ca}^{2+}\right]_{i}$ in whole hearts during autonomic stimulation.

\section{Role of the renin-angiotensin system}

Angiotensin II. The renin-angiotensin system (RAS) is an enzymatic cascade that controls conversion of angiotensinogen into angiotensin II. The final step in this process is mediated by ACE. For- mation of angiotensin II occurs systemically and also locally in the heart. Increased levels of angiotensin II have several adverse effects on the cardiovascular system, including cardiomyocyte hypertrophy, facilitation of norepinephrine release from its prejunctional sites, fibroblast and smooth muscle proliferation, and vasoconstriction. In cardiomyocytes, chronic stimulation of the angiotensin receptor-coupled G $\alpha$ /phospholipase C/PKC pathway can downregulate the activity of several key $\mathrm{Ca}^{2+}$-handling proteins via phosphatase-mediated dephosphorylation (Figure 2). Interruption of RAS by means of pharmacologic inhibition of $\mathrm{ACE}$ and/or angiotensin II receptor blockade decreases cardiovascular morbidity and mortality in patients with left-ventricular dysfunction (58-61). However, whether the reduction in mortality results, at least in part, from a decrease in the incidence of death from arrhythmias was not demonstrated. Experimental studies show that abnormal regulation of RAS in cardiovascular disease may increase the susceptibility to arrhythmias. Mice in which angiotensin II was elevated via genetic clamping exhibit marked cardiac hypertrophy, bradycardia due to atrioventricular conduction defects, T-wave alternans, and a high frequency of SCD from arrhythmias (62). Mice with cardiomyocyte-specific overexpression of ACE-related carboxypeptidase capable of cleaving angiotensin II exhibit downregulation of connexin-40 and connexin-43, complete atrioventricular block, and an increased rate of SCD from ventricular arrhythmias, which suggests that RAS controls connexin expression in the heart (63).

Intriguingly, alterations in the RAS also affect peripheral and central sympathetic function. In rat postganglionic sympathetic neurons, angiotensin II acutely inhibits voltage-dependent $\mathrm{N}$-type $\mathrm{Ca}^{2+}$ currents and repolarizing $\mathrm{K}^{+}$currents (64), possibly resulting in altered excitation-secretion coupling of peripheral sympathetic neurons. Transgenic rats deficient in brain angiotensinogen exhibited better preservation of left-ventricular function, arterial baroreflex control, and renal sympathetic nerve activity following myocardial infarction than did nontransgenic rats (65). In rabbits with rapid pacing-induced chronic heart failure, blockade of angiotensin II receptors combined with administration of exogenous NO reduces elevated renal sympathetic nerve activity, which suggests that both loss of $\mathrm{NO}$ and an increase in angiotensin II are necessary for sympathoexcitation in chronic heart failure (66). It is still unknown whether preservation of normal sympathetic function translates into a reduction in the incidence of cardiac arrhythmias.

Effect of angiotensin II on ion channels and transporters. Angiotensin II has also been shown to directly modulate ion channels and transporters. Inhibition by angiotensin II of voltage-dependent, repolarizing $\mathrm{K}^{+}$currents in arterial smooth muscle causes vasoconstriction $(67,68)$, possibly leading to reduced myocardial blood flow in conditions associated with elevated angiotensin II. In cardiomyocytes, enhancement of $\mathrm{I}_{\mathrm{Ca.L}}$; reduction of the delayed rectifier $\mathrm{K}^{+}$current, $\mathrm{I}_{\mathrm{K}}$, and the transient outward $\mathrm{K}^{+}$current, $\mathrm{I}_{\text {to }}$; and electrogenic $\mathrm{Na} / \mathrm{K}$ ATPase activity act synergistically to prolong action potential duration and to increase intracellular $\mathrm{Ca}^{2+}$ load, thereby promoting arrhythmia susceptibility. ACE inhibitors, as well as angiotensin receptor blockers, reduce SCD in heart failure and postinfarction patients (58-61). Passive stretch elicits an outwardly rectifying $\mathrm{Cl}^{-}$current in ventricular myocytes by a mechanism that involves release of angiotensin II and activation of angiotensin II type 1 receptor in an autocrine/paracrine loop (69).

Aldosterone. Angiotensin II also enhances release of aldosterone from the adrenal cortex. Aldosterone has potent sodium-retaining 
properties and can exert adverse cardiovascular effects, including myocardial hypertrophy and fibrosis. Like angiotensin II, aldosterone regulates cardiac ion channels. Chronic exposure of rat ventricular myocytes to aldosterone reduces and increases, respectively, $\mathrm{I}_{\text {to }}$ and $\mathrm{I}_{\mathrm{Ca} . \mathrm{L}}(70)$. The temporal relationship of the changes in current densities and the effect of blockers of the $\mathrm{I}_{\mathrm{Ca.L}}$ are consistent with the $\mathrm{Ca}^{2+}$-dependent reduction of $\mathrm{I}_{\mathrm{to}}$ expression. In a postmyocardial infarction model of heart failure in rats, aldosterone antagonism had a number of effects, including inhibiting fibrosis, reducing myocardial norepinephrine content, and increasing the VF threshold (71). Clinically, treatment with the aldosterone receptor antagonists spironolactone or eplerenone has been demonstrated to reduce SCD in heart failure patients $(72,73)$.

Collectively, these observations suggest that elevated angiotensin II and/or aldosterone levels exert adverse electrophysiological effects that may contribute to the development of a proarrhythmic substrate in conditions that are typically associated with abnormal activation of the RAS (e.g., heart failure). Antagonizing their effects could reduce the extent of adverse electrical remodeling and has been shown to prevent SCD. Because RAS signaling also has profound effects on heart structure, including induction of hypertrophy and interstitial fibrosis, it will be important to determine whether antiarrhythmic effects of RAS signaling antagonists derive indirectly from preservation of the structural integrity of the heart, directly from modulation of ion channels and transporters, or both.

\section{Genetic predisposition}

In addition to well-known heritable genetic disorders such as LQTS, genetic variations exist that determine an individual's risk for fatal arrhythmias. In the Paris Prospective study, a history of SCD in 1 parent was shown to increase the risk of fatal arrhythmia in the offspring by $80 \%$; a history of SCD in both parents leads to an approximate 9-fold increase in the risk of SCD for the offspring (74). In another population-based study, the rate of SCD in first-degree relatives of SCD victims was $50 \%$ greater than the rate in control subjects and, importantly, was independent of other risk factors such as diabetes, hypertension, or cigarette smoking (75). It is very likely that a number of genes contribute to the phenotypic manifestation of SCD. Contributors may include known or unknown genes associated with myocardial ischemia, neurohumoral signaling, cardiomyocyte $\mathrm{Ca}^{2+}$ handling, and cardiac electrical properties. Once genetic factors have been identified by genomic screening, the major challenge will be to determine whether a specific gene variant constitutes a specific marker of the risk for SCD independently of the underlying structural heart disease and what role this variant plays in the pathogenesis of fatal arrhythmias.

\section{Prevention of SCD from arrhythmia}

Chronic beta blockade improves survival in patients after myocardial infarction $(4,76)$, reducing the incidence of SCD, par- ticularly in patients with impaired left-ventricular function. The use of some compounds, such as encainide, flecainide, and D-sotalol, that block specific cardiac ion channels, i.e., "classic" antiarrhythmic drugs, has been shown to be associated with an adverse outcome in patients with chronic myocardial infarction $(3,77)$. Amiodarone, an antiarrhythmic agent, which at clinically relevant concentrations blocks a variety of cardiac ion channels and transporters, including sodium channels, L-type calcium channels, several types of potassium channels, and the sodiumcalcium exchanger, and which inhibits $\alpha$ - and $\beta$-adrenergic receptors (78), also does not improve survival (79-81). Therefore, prophylactic use of specific ion channel blockers does not reduce mortality or may even increase it. In contrast, ICDs confer survival benefit compared with drugs in high-risk populations (2). ICD therapy is now standard care for patients who have survived life-threatening arrhythmias (2).

Patients with heart failure commonly have regions of delayed myocardial activation and contraction, which leads to cardiac dyssynchrony. Cardiac resynchronization, which entails placement of a right-atrial, a right-ventricular, and a left-ventricular lead, restores atrio-biventricular synchrony resulting in improved leftventricular function and (without concomitant ICD therapy) can improve survival in patients with heart failure (ejection fraction $<35 \%$ ) and cardiac dyssynchrony (82).

\section{Conclusion}

The purpose of this review was to consider some of the many events that can transform an electrically stable heart into one that is unstable, in order to answer the clinical question of why a particular patient died at a particular time on a particular day and not at another time. This is one of the most important (and vexing) questions in clinical cardiology today, as it entails exploration of the proximate precipitators of SCD (83) in order to help identify the individual at risk. Because of space constraints, we have only discussed several of the many factors that may be important. The list is long and can be approached by considering fundamental molecular mechanisms, cellular changes, whole heart electrophysiology, and clinical risk factors. Nevertheless, it is an area richly deserving intense investigation if we are ever going to reduce the horrendous toll claimed by SCD.

\section{Acknowledgments}

This work was supported by grants from the Hermann C. Krannert Fund and the NIH (HL075165 to M. Rubart).

Address correspondence to: Michael Rubart, Herman B. Wells Center for Pediatric Research, Indiana University School of Medicine, 1044 West Walnut Street, Indianapolis, Indiana 462025225, USA. Phone: (317) 274-2207; Fax: (317) 278-5413; E-mail: mrubartv@iupui.edu.

\footnotetext{
1. Huikuri, H.V., Castellanos, A., and Myerburg, R.J. 2001. Sudden death due to cardiac arrhythmias. N. Engl. J. Med. 345:1473-1482.

2. Yadav, A.V., Das, M., and Zipes, D.P. 2005. Selection of patients for ICDs: 'where are we in 2005?'. ACC Curr. J. Review. 14:33-37.

3. Echt, D.S., et al. 1991. Mortality and morbidity in patients receiving encainide, flecainide, or placebo: the Cardiac Arrhythmia Suppression Trial. N. Engl. J. Med. 324:781-788.

4. Gottlieb, S.S., McCarter, R.J., and Vogel, R.A. 1998. Effect of beta-blockade on mortality among high-
}

risk and low-risk patients after myocardial infarction. N. Engl. J. Med. 339:489-497.

5. Alberte, C., and Zipes, D.P. 2003. Use of nonantiarrhythmic drugs for prevention of sudden cardiac death. J. Cardiovasc. Electrophysiol. 14:S87-S95.

6. Tomaselli, G.F., and Zipes, D.P. 2004. What causes sudden death in heart failure? Circ. Res. 95:754-763.

7. Arking, D.E., Chugh, S.S., Chakravarti, A., and Spooner, P.M. 2004. Genomics in sudden cardiac death. Circ. Res. 94:712-723.

8. Chen, P.S., et al. 2003. A tale of two fibrillations. Circulation. 108:2298-2303.
9. Huikuri, H.V., et al. 2003. Prediction of sudden cardiac death: appraisal of the studies and methods assessing the risk of sudden arrhythmic death. Circulation. 108:110-115.

10. Marx, S.O., et al. 2000. PKA phosphorylation dissociates FKBP12.6 from the calcium release channel (ryanodine receptor): defective regulation in failing hearts. Cell. 101:365-376.

11. Wehrens, X.H.T., et al. 2003. FKBP12.6 deficiency and defective calcium release channel (ryanodine receptor) function linked to exercise-induced sudden cardiac death. Cell. 113:829-840. 
12. Mohler, P.J., et al. 2003. Ankyrin-B mutation causes type 4 long-QT cardiac arrhythmia and sudden cardiac death. Nature. 421:634-639.

13. Viatchenko-Karpinski, S., et al. 2004. Abnormal calcium signaling and sudden cardiac death associated with mutation of calsequestrin. Circ. Res. 94:471-477.

14. Xin, H.B., et al. 2002. Oestrogen protects FKBP12.6 null mice from cardiac hypertrophy. Nature. 416:334-338

15. Fabiato, A., and Fabiato, F. 1975. Contractions induced by a calcium-triggered release of calcium from the sarcoplasmic reticulum of single skinned cardiac cells. J. Physiol. 249:469-495.

16. Wehrens, X.H.T., et al. 2004. Protection from cardiac arrhythmia through ryanodine receptor-stabilizing protein calstabin2. Science. 304:292-296.

17. Wier, W.G., ter Keurs, H.E., Marban, E., Gao, W.D., and Balke, C.W. 1997. $\mathrm{Ca}^{2+}$ 'sparks' and waves in intact ventricular muscle resolved by confocal imaging. Circ. Res. 81:462-469.

18. Schlotthauer, K., and Bers, D.M. 2000. Sarcoplasmic reticulum $\mathrm{Ca}(2+)$ release causes myocyte depolarization. Underlying mechanism and threshold for triggered action potentials. Circ. Res. 87:774-780.

19. Baader, A.P., Buchler, L., Bircher-Lehmann, L., and Kleber, A.G. 2001. Real time, confocal imaging of $\mathrm{Ca}^{2+}$ waves in arterially perfused rat hearts. Cardiovasc. Res. 53:105-115.

20. Tanaka, H., Oyamada, M., Tsujii, E., Nakajo, T., and Takamatsu, T. 2002. Excitation-dependent intracellular $\mathrm{Ca}^{2+}$ waves at the border zone of the cryo-injured rat heart revealed by real-time confocal microscopy. J. Mol. Cell. Cardiol. 34:1501-1512.

21. Ai, X., and Pogwizd, S.M. 2005. Connexin 43 downregulation and dephosphorylation in nonischemic heart failure is associated with enhanced colocalized protein phosphatase type $2 \mathrm{~A}$ Circ. Res. 96:54-63.

22. Yao, J.A., et al. 2003. Remodeling of gap junctional channel function in epicardial border zone of healing canine infarcts. Circ. Res. 92:437-443.

23. Pogwizd, S.M., Schlotthauer, K., Li, L., Yuan, W., and Bers, D.M. 2001. Arrhythmogenesis and contractile dysfunction in heart failure: roles of sodium-calcium exchange, inward rectifier potassium current, and residual beta-adrenergic responsiveness. Circ. Res. 88:1159-1167.

24. Pogwizd, S.M. 1995. Nonreentrant mechanism underlying spontaneous ventricular arrhythmias in a model of nonischemic heart failure in rabbits. Circulation. 92:1034-1048.

25. Pogwizd, S.M., McKenzie, J.P., and Cain, M.E. 1998. Mechanisms underlying spontaneous and induced ventricular arrhythmias in patients with idiopathic dilated cardiomyopathy. Circulation. 98:2404-2414.

26. Qin, D., et al. 1996. Cellular and ionic basis of arrhythmias in postinfarction remodeled ventricular myocardium. Circ. Res. 79:461-473.

27. Wu, J., and Zipes, D.P. 2001. Transmural reentry during global acute ischemia and reperfusion in canine ventricular muscle. Am. J. Physiol. 280:H2717-H2725.

28. Takahashi, T., et al. 2004. Optical mapping of the functional circuit of ventricular tachycardia in acute myocardial infarction. Heart Rhythm. 4:451-459.

29. Choi, B., Burton, F., and Salama, G. 2002. Cytosolic $\mathrm{Ca}^{2+}$ triggers early afterdepolarizations and torsade de pointes in rabbit hearts with type 2 long QT syndrome. J. Physiol. 543:615-631.

30. Ueda, N., Zipes, D.P., and Wu, J. 2004. Prior ischemia enhances arrhythmogenicity in isolated canine ventricular wedge model of long QT 3. Cardiovasc. Res. 63:69-76.

31. Omichi, C., et al. 2004. Intracellular Ca dynamics in ventricular fibrillation. Am. J. Physiol. Heart Circ. Physiol. 286:H1836-H1844.

32. Nearing, B.D., Huang, A.H., and Verrier, R.L. 1991. Dynamic tracking of cardiac vulnerability by complex demodulation of the $\mathrm{T}$ wave. Science. 252:437-440

33. Pruvot, E.J., Katra, R.P., Rosenbaum, D.S., and Laurita, K.R. 2004. Role of calcium cycling versus restitution in the mechanism of repolarization alternans. Circ. Res. 94:1083-1090.

34. Goldhaber, J.I., et al. 2005. Action potential duration restitution and alternans in rabbit ventricular myocytes: the key role of intracellular calcium cycling. Circ. Res. 96:459-466.

35. Chudin, E., Goldhaber, J., Garfinkel, A., Weiss, J., and Kogan, B. 1999. Intracellular $\mathrm{Ca}(2+)$ dynamics and the stability of ventricular tachycardia. Biophys. $J$. 77:2930-2941.

36. Wingo, T.L., et al. 2004. An EF-hand in the sodium channel couples intracellular calcium to cardiac excitability. Nat. Struct. Mol. Biol. 11:219-225.

37. Wu, Y., Roden, D.M., and Anderson, M.E. 1999. Calmodulin kinase inhibition prevents development of the arrhythmogenic transient inward current. Circ. Res. 84:906-912.

38. Wu, Y., et al. 2002. Calmodulin kinase II and arrhythmias in a mouse model of cardiac hypertrophy. Circulation. 106:1288-1293.

39. Xu, Y., et al. 2005. The effect of intracellular $\mathrm{Ca}^{2+}$ on cardiac $\mathrm{K}^{+}$channel expression and activity: novel insights from genetically altered mice. J. Physiol. 562:745-758.

40. Zipes, D.P., and Wellens, H.J.J. 1998. Sudden cardiac death. Circulation. 98:2334-2351.

41. Shivkumar, K., et al.1997. Mechanism of hypoxic K loss in rabbit ventricle. J. Clin. Invest. 100:1782-1788.

42. John, S.A., Kondo, R., Wang, S.Y., Goldhaber, J.I., and Weiss, J.N. 1999. Connexin-43 hemichannels opened by metabolic inhibition. J. Biol. Chem. 274:236-240

43. Yan, G.X., Park, T.H., and Corr, P.B. 1995. Activation of thrombin receptor increases intracellular $\mathrm{Na}^{+}$during myocardial ischemia. Am. J. Physiol. 268:H1740-H1748.

44. Kaneko, T., Tanaka, H., Oyamada, M., Kawata, S., and Takamatsu, T. 2000. Three distinct types of $\mathrm{Ca}^{(2+)}$ waves in Langendorff-perfused rat heart revealed by real-time confocal microscopy. Circ. Res. 86:1093-1099.

45. Verkerk, A.O., Veldkamp, M.W., Coronel, R., Wilders, R., and van Ginneken, A.C. 2001. Effects of cell-tocell uncoupling and catecholamines on Purkinje and ventricular action potentials: implications for phase-1b arrhythmias. Cardiovasc. Res. 51:30-40.

46. Woodcock, E.A., Arthur, J.F., Harrison, S.N., Gao, X., and Du, X. 2001. Reperfusion-induced Ins $(1,4,5) \mathrm{P} 3$ generation and arrhythmogenesis require activation of the $\mathrm{Na}+/ \mathrm{Ca} 2+$ exchanger. J. Mol. Cell. Cardiol. 33:1861-1869.

47. Imahashi, K., et al. 1999. Intracellular sodium accumulation during ischemia as the substrate for reperfusion injury. Circ. Res. 84:1401-1406.

48. Ueda, N., Zipes, D.P., and Wu, J. 2004. Functional and transmural modulation of $\mathrm{M}$ cell behavior in canine ventricular wall. Am. J. Physiol. Heart Circ. Physiol. 287:H2569-H2575.

49. Lakireddy, V., et al. 2005. Contrasting effects of ischemia on the kinetics of membrane voltage and intracellular calcium transient underlie electrical alternans. Am. J. Physiol. Heart Circ. Physiol. 288:H400-H407.

50. Cao, J.M., et al. 2000. Nerve sprouting and sudden cardiac death. Circ. Res. 86:816-821.

51. Liu, Y., et al. 2003. Sympathetic nerve sprouting, electrical remodeling, and increased vulnerability to ventricular fibrillation in hypercholesterolemic rabbits. Circ. Res. 92:1145-1152.

52. Cao, J.M., et al. 2000. Relationship between regional cardiac hyperinnervation and ventricular arrhythmia. Circulation. 101:1960-1969.

53. Heath, B.M., et al. 1998. Overexpression of nerve growth factor in the heart alters ion channel activity and $\beta$-adrenergic signaling in an adult transgenic mouse. J. Physiol. 512:779-791.

54. Barber, M.J., Mueller, T.M., Henry, D.P., Felten, S.Y., and Zipes, D.P. 1983. Transmural myocardial infarction in the dog produces sympathectomy in noninfarcted myocardium. Circulation. 67:787-796.

55. Warner, M.R., Wisler, P.L., Hodges, T.D., Watanabe, A.M., and Zipes, D.P. 1993. Mechanisms of denervation supersensitivity in regionally denervated canine hearts. Am. J. Physiol. 264:H815-H820.

56. Komaru, T., et al. 1990. Neuropeptide Y modulates vasoconstriction in coronary microvessels in the beating canine heart. Circ. Res. 67:1142-1151.

57. Protas, L., et al. 2003. Neuropeptide Y is an essential in vivo developmental regulator of cardiac ICa,L. Circ. Res. 93:972-979.

58. Pfeffer, M.A., et al. 2003. Valsartan, captopril, or both in myocardial infarction complicated by heart failure, left ventricular dysfunction, or both. N. Engl. J. Med. 349:1893-1906.

59. Pfeffer, M.A., et al. 1992. Effect of captopril on mortality and morbidity in patients with left ventricular dysfunction after myocardial infarction. Results of the survival and ventricular enlargement trial. The SAVE Investigators. N. Engl. J. Med. 327:669-677.

60. The SOLVD Investigators. 1992. Effect of enalapril on mortality and the development of heart failure in asymptomatic patients with reduced left ventricular ejection fractions. N. Engl. J. Med. 327:685-691.

61. Cohn, J.N., Tognoni, G., and Valsartan Heart Failure Trial Investigators. 2001. A randomized trial of the angiotensin-receptor blocker valsartan in chronic heart failure. N. Engl. J. Med. 345:1667-1775.

62. Caron, K.M., et al. 2004. Cardiac hypertrophy and sudden death in mice with a genetically clamped renin transgene. Proc. Nat. Acad. Sci. U. S. A. 101:3106-3111.

63. Donoghue, M., et al. 2003. Heart block, ventricular tachycardia, and sudden death in ACE2 transgenic mice with downregulated connexins. J. Mol. Cell. Cardiol. 35:1043-1053.

64. Shapiro, M.S., Wollmuth, L.P., and Hille, B. 1994. Angiotensin II inhibits calcium and M current in rat sympathetic neurons via $G$ proteins. Neuron. 12:1319-1329.

65. Wang, H., Huang, B.S., Ganten, D., and Leenen, F.H.H. 2004. Prevention of sympathetic and cardiac dysfunction after myocardial infarction in transgenic rats deficient in brain angiotensinogen. Circ. Res. 94:843-849.

66. Liu, J., and Zucker, I.H. 1999. Regulation of sympathetic nerve activity in heart failure. Circ. Res. 84:417-423.

67. Toro, L., Amador, M., and Stefani, E. 1990. ANG II inhibits calcium-activated potassium channels from coronary smooth muscle in lipid bilayers. Am. J. Physiol. 258:H912-H915.

68. Gelband, C.H., and Hume, J.R. 1995. $\left[\mathrm{Ca}^{2+}\right]_{\mathrm{i}}$ inhibition of $\mathrm{K}^{+}$channels in canine renal artery. Novel mechanism for agonist-induced membrane depolarization. Circ. Res. 77:121-130.

69. Browe, D.M., and Baumgarten, C.M. 2004. Angiotensin II (AT1) receptors and NADPH oxidase regulate $\mathrm{Cl}^{-}$current elicited by $\beta 1$ integrin stretch in rabbit ventricular myocytes. J. Gen. Physiol. 14:273-287.

70. Benitah, J.P., Perrier, E., Gomez, A.M., and Vassort, G. 2001. Effects of aldosterone on transient outward $\mathrm{K}^{+}$current density in rat ventricular myocytes. J. Physiol. 537:151-160.

71. Cittadini, A., et al. 2003. Aldosterone receptor blockade improves left ventricular remodeling and increases ventricular fibrillation threshold in experimental heart failure. Cardiovasc. Res. 58:555-564. 


\section{science in medicine}

72. Pitt, B., et al. 2003. The effect of spironolactone on morbidity and mortality in patients with severe heart failure. N. Engl. J. Med. 341:709-717.

73. Pitt, B., et al. 2003. Eplerenone, a selective aldosterone blocker, in patients with left ventricular dysfunction after myocardial infarction. N. Engl. J. Med. 348:1309-1321.

74. Jouven, X., Desnos, M., Guerot, C., and Ducimetiere, P. 1999. Predicting sudden death in the population: the Paris Prospective Study I. Circulation. 99:1978-1983.

75. Friedlander, Y., et al. 1998. Family history as a risk factor for primary cardiac arrest. Circulation. 97:155-160.

76. Yusuf, S., Peto, R., Lewis, J., Collins, R., and Sleight, P. 1985. Beta blockade during and after myocardial infarction: an overview of the randomized trials. Prog. Cardiovasc. Dis. 27:335-371.
77. Waldo, A.L., et al. 1996. Effect of d-sotalol on mortality in patients with left ventricular dysfunction after recent and remote myocardial infarction. The SWORD Investigators. Survival With Oral d-Sotalol. Lancet. 348:7-12.

78. Watanabe, Y., and Kimura, J. 2000. Inhibitory effect of amiodarone on $\mathrm{Na}^{+} / \mathrm{Ca}^{2+}$ exchange in guinea-pig cardiomyocytes. Br. J. Pharmacol. 131:80-84.

79. Julian, D.G., et al. 1997. Randomised trial of effect of amiodarone on mortality in patients with left-ventricular dysfunction after recent myocardial infarction: EMIAT. European Myocardial Infarct Amiodarone Trial Investigators. Lancet. 349:667-674.

80. Cairns, J.A., Connolly, S.J., Roberts, R., and Gent, M. 1997. Randomised trial of outcome after myocardial infarction in patients with frequent or repetitive ventricular premature depolarisations: CAMIAT. Canadian Amiodarone Myocardial
Infarction Arrhythmia Trial Investigators. Lancet. 349:675-682.

81. Bardy, G.H., et al. 2005. Amiodarone or an implantable cardioverter-defibrillator for congestive heart failure. N. Engl. J. Med. 352:225-237.

82. Cleland, J.G., et al. 2005. The effect of cardiac resynchronization on morbidity and mortality in heart failure. N. Engl. J. Med. 352:1539-1549.

83. Zipes, D.P. 2003. Less heart is more. Circulation. 107:2531-2532.

84. Yano, M., Ikeda, Y., and Matsuzaki, M. 2005. Altered intracellular $\mathrm{Ca}^{2+}$ handling in heart failure. J. Clin. Invest. 115:556-564. doi:10.1172/JCI200524159.

85. Subramanian, S., Viatchenko-Karpinski, S., Lukyanenko, V., Gyorke, S., and Wiesner, T.F. 2001. Underlying mechanisms of symmetric calcium wave propagation in rat ventricular myocytes. Biophys. J. 80:1-11. 